ISSN: 2640-9666

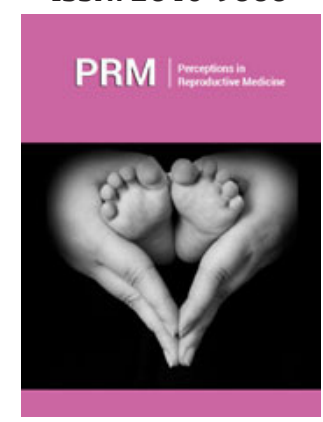

*Corresponding author: John Townsend, The Population Council, USA.

Submission: 酶 November 11, 2019

Published: November 15, 2019

Volume 3 - Issue 4

How to cite this article: John Townsend and Elspeth Williams. The Great Debate: Do We Need New Contraceptive Methods to Ensure More Choice?. Perception in Reproductive Medicine.3(4). PRM.000568.2019.

DOI: $10.31031 /$ PRM.2019.03.000568

Copyright@ John Townsend, This article is distributed under the terms of the Creative Commons Attribution 4.0 International License, which permits unrestricted use and redistribution provided that the original author and source are credited.

\section{The Great Debate: Do We Need New Contraceptive Methods to Ensure More Choice?}

\author{
John Townsend* and Elspeth Williams
}

The Population Council, USA

\section{Opinion}

The call for safer, more effective contraceptive methods is not the same as ensuring informed choice and access to users in countries around the world. But these two diverse perspectives have dominated the debate between health scientists and contraceptive service providers on the best investments in reproductive health and medicine for the last 50 years. Recently, the members of a US-based community of practice (COP) entitled "LARC \& Permanent Methods COP met in Washington DC to focus on how best to expand method choice and discuss what it takes to operationalize method choice at the country level. After a series of panels beautifully illustrating the data globally on method use and choice from Demographic and Health Surveys (DHS), procurement data and commodity gaps from the Reproductive Health Supplies Coalition, community-based perspectives on new methods from FHI360, and a review from Performance Monitoring and Accountability 2020 on the underlying dynamics affecting method adoption, continuation and switching among users in developing countries, the COP examined the conditions and environment required to ensure method choice for users as well as the service delivery policies and investments that shape the types of choices available to users, and the requirements for providers and procurement agencies alike.

Financial Gap: Service and/or R\&D?

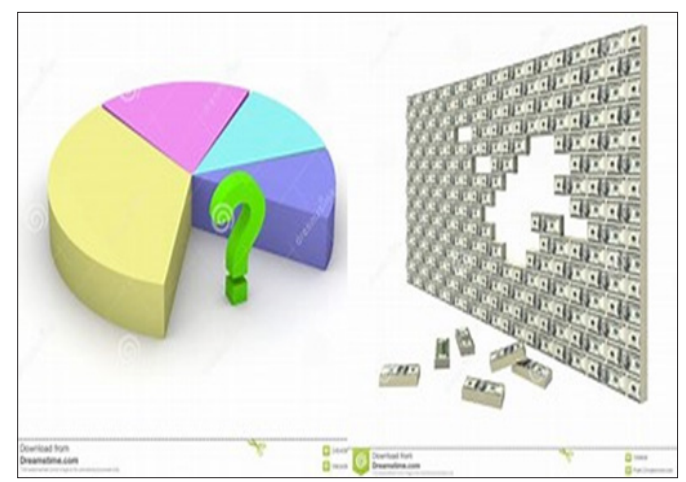

Figure 1:

But the big issue, given the current lean funding environment for family planning is how do we invest for the future. Are we satisfied with the current range of contraceptive methods (e.g. pills, condoms, injectables, IUD/IUS, emergency contraception, and permanent methods such as tubectomy and vasectomy) for women and men, or do we invest in both developing new products to address the concerns of current and potential clients while we try to expand the range of products that are available in any given country or market. Methods are not the same as brands see conceptual image in Figure 1. For example, Peru may offer clients over 20 brands of emergency contraception (EC), but from a client perspective EC remains a single method. To shape the debate, the COP called on two highly experienced professionals, e.g. Laneta Dorflinger PhD from FHI360 and Roy Jacobstein MD from IntraHealth to make the case for expanding the array of new methods versus focusing on getting available methods to underserved populations. Dr. Dorflinger highlighted the challenges with current methods, including users' complaints about side effects, the high rate of discontinuation of spacing methods, and the desire for alternatives. Women in several countries in Africa overwhelming 
asked for "something better, something new, something that meets their needs". Typically, women use 3-4 methods over their 35year reproductive lifespan (15-49 years), while men are left with withdrawal, condoms and vasectomy.The level of investment in research on new contraceptive technologies globally was less than US $\$ 70$ million in 2015, a fraction of what Americans spend on holiday treats in any given year and well below the investments in the development of other health technologies, e.g. HIV prevention, malaria or polio prevention. Laneta made the strong case that investments in safer, more effective and acceptable contraceptives not only prevent unintended pregnancies, it also allows women to take on other roles in business, government and community leadership that contribute to a range of Sustainable Development Goals.

\section{Contraceptive Options in Global Market in 2019}

Agreeing that choice is undeniably good, Dr. Jacobstein maintained that investments in new technology now would take funding away for the delivery of services when they are most needed, and that the benefits of new technologies would not likely reach clients for another twenty years. Moreover, most of the innovations that have benefited women in the family planning in developing countries were not technologies per se but rather new ways of delivering services, such as social marketing, community outreach, training of trainers for quality improvement and the recent use of digital technologies for forecasting demand, management of supply chains and for counseling as seen in Kenya and India (e.g. Nivi: A digital marketplace for family planning). Dr. Jacobstein maintained that side effects and complaints based on user preferences and lifestyle would never be eliminated, even for methods that did not rely on the use of hormones. As might be suspected (Figure 2 ), there were those in the audience that were concerned about the pharmaceutical industry making undue profit on new more expensive technologies. Others challenged the community from a gender perspective, indicating that more research was needed for male methods, so that men could better share the cost and burden of more than 35 years of contraceptive use.

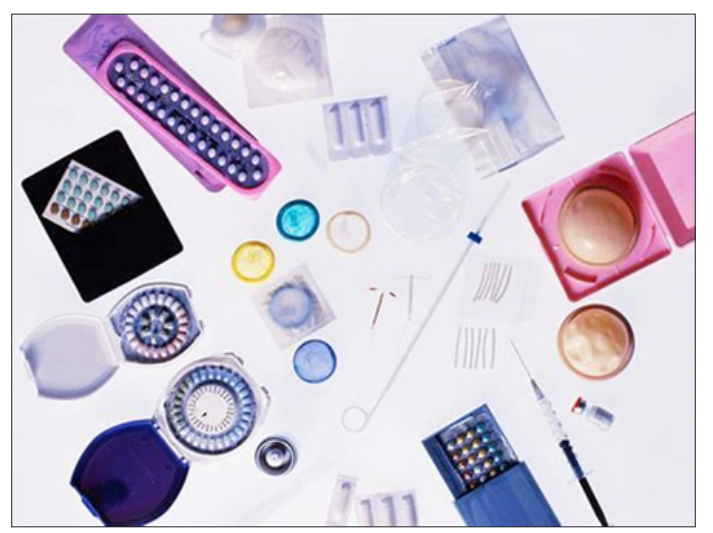

Figure 2:

It is doubtful that most funding for R\&D would ever be used for service delivery, so a direct tradeoff is unlikely. Finally, the level of resources required for shifting the contraceptive landscape are largely unknown currently as the costs are embedded in an array of activities including basic biomedical research on new mechanisms, product development, large clinical trials, regulatory review and approval, procurement and introduction. One informant asked, "How many new methods will be needed to meet the aspirations of all." As might be expected given the audience, the COP acknowledged that investments in both R\&D and new service delivery had to happen simultaneously to meet the growing needs of both adolescents and women who have reached their desired family size. And given the new gender perspectives, more attention must be addressed to creating methods for men that will benefit both women and male users. As countries move toward middle income, individuals may change their cell phone every five years, or go to the salon or gym or barbershop more regularly to feel healthy. These are indicators of a growing market for contraception as a key element for making better development choices for themselves and their families. In closing the discussion, we reminded the audience of the perspective of a growing wave of advocates, "We don't want our daughters to use their grandmother's contraceptive." We have to invest for the future in education, vibrant economies, health promotion and choice. Contraception has to be part of that basket of choices.

For possible submissions Click below: 